\title{
Analysis of Learning Management System Features based on Indonesian Higher Education National Standards using the Feature-Oriented Domain Analysis
}

\author{
$1^{\text {st }}$ Galih Wasis Wicaksono \\ Departments of Informatics \\ Universitas Muhammadiyah Malang \\ Malang, Indonesia \\ galih.w.w@umm.ac.id \\ $4^{\text {th }}$ Yus Mochamad Cholily \\ Departments of Mathematics \\ Universitas Muhammadiyah Malang \\ Malang, Indonesia \\ yus@umm.ac.id
}

\author{
$2^{\text {nd }}$ Ghina Arih Juliani \\ Departments of Informatics \\ Universitas Muhammadiyah Malang \\ Malang, Indonesia \\ ghinaarih@umm.ac.id \\ $5^{\text {th }}$ Hari Windu Asrini \\ Indonesian Language \\ Universitas Muhammadiyah Malang \\ Malang, Indonesia \\ yus@umm.ac.id
}

\author{
$3^{\text {rd }}$ Evi Dwi Wahyuni \\ Departments of Informatics \\ Universitas Muhammadiyah Malang \\ Malang, Indonesia \\ evidwi@umm.ac.id \\ $6^{\text {th }}$ Budiono \\ Indonesian Language \\ Universitas Muhammadiyah Malang \\ Malang, Indonesia \\ budiono@umm.ac.id
}

\begin{abstract}
Various studies on the Learning Management System (LMS) have not examined the suitability of LMS features with the educational standards applicable in a country/region. This study aims to measure the suitability of LMS features with the National Higher Education Standards/ Standar Nasional Pendidikan Tinggi (SN-Dikti) in Indonesia using the Feature-Oriented Domain Analysis (FODA) method. This research identifies explicitly LMS features in the assignment and assessment functions. Besides, this study recommends previous LMS features for future LMS development based on the assessment standards applicable in Indonesia. The results of the analysis in this study found the suitability of the three LMS and recommended LMS features for Lecturer and Student users.
\end{abstract}

Keywords—Learning Management System, SN-Dikti, FODA

\section{INTRODUCTION}

The function of Learning Management System (LMS) as an information technology product in the field of education, especially higher education, namely: 1) facilitating lecturers and students in achieving learning objectives; 2) assignments and assessments or online grade books; 3 ) class management such as the distribution of handouts, announcements or sending emails between users and others [1], [2]. The use of LMS in higher education is used in the form of online learning or combined with classroom learning / blended learning.

There are many LMS with various categories and various features that have been utilized, primarily in Higher Education, for example, the types of open-source LMS such as Moodle, Blackboard Courses, Schoology and others; Besides, there are also Proprietary LMS like Blackboard Learn and WebCT; other categories are Software as a Service (SAAS) / Cloud-based LMS such as Edmodo, Canvas, Google Classroom, and others.

LMS analyzed in this study, namely Edmodo, Google Classroom, and Moodle. The main factor for the selection of the three LMS is because first, the three LMS are used in tertiary institutions to be the object of observation. The application of pedagogical strategies in the LMS is studied as in Moodle become another aspect [2]. Next, LMS was chosen, which has characteristics, such as Edmodo with characteristics of social network sites in education [3], or Moodle with various features offered [1].
Another aspect that is a problem is the mapping of LMS with the National Higher Education Standards/Standar Nasional Pendidikan Tinggi (SN-Dikti). SN-Dikti has been established through the Minister of Research and Technology and Higher Education Regulation (Permenristekdikti) No. 44 of 2015. SN-Dikti as the standardization of Higher Education in Indonesia consists of 3 standards, namely 1) National Education Standards; 2) National Research Standards; and 3) National Standards of Community Service. The National Education Standards then consist of 8 standards.

System standardization based on national qualifications framework or educational standards applicable in a country has been used in Thailand, namely by using the Thailand Qualification Framework as a reference for the design of cloud services architecture [4].

One standard that is the focus of mapping in this study is the assessment standard. Learning assessment standards become the minimum criteria regarding the assessment of student learning processes and outcomes in the context of fulfilling graduate learning outcomes. Assessment of student learning processes and outcomes includes assessment principles, assessment techniques, and instruments, assessment mechanisms and procedures, conducting assessments, and reporting assessment and student graduation.

The standards raised in this study are learning and assessment standards. This standard was chosen because based on the results of observations, the features most used in the three LMS are learning and assessment features. The assessment and assignment features on three LMS will be analyzed using domain analysis. Domain analysis can provide a reference model for describing classes, provide a basis for understanding and communication about the scope of problems handled by software, and can propose a series of architectural approaches to implement in new systems. One domain analysis used is Feature-Oriented Domain Analysis (FODA).

The feature-oriented concept is based on the method's emphasis on identifying features expected by users. The FODA method analyzes the domain by focusing on identifying features in a piece of software. FODA has three necessary activities, namely: context analysis, domain modeling, and architecture modeling [5]. 
The reason for choosing FODA is because this method can provide several ways of applying the results of domain analysis to support software development. FODA supports the reuse of features from a pre-existing system. This can be used in the context, modeling, and architecture stages. Based on these advantages, feature modeling using FODA has been used in various systems research and development, such as developing the FODA framework for energy-aware applications configuration [6] and in the development of Mobile media [7].

The variety of LMS along with superior features in each LMS, requires a variety of analysis and measurement of the use of LMS such as usability [8], user experience [9], and others. However, from various studies that have been conducted, there has been no study on the suitability of LMS features with the applicable Education standards in a country or region.

This study offers measurement of the suitability of LMS features in the assessment and assignment domains as well as alignment with SN-DIKTI. This research focuses on the assignment and assessment functions of three LMS. This study also observed the application of LMS in one of the Higher Education Institutions that allowed the use of various types of LMS.

\section{RESEARCH METHODS}

This research goes through the stages in the FODA flow by adding a requirement identification phase before the analysis phase with FODA. Figure 1 shows the entire research method.

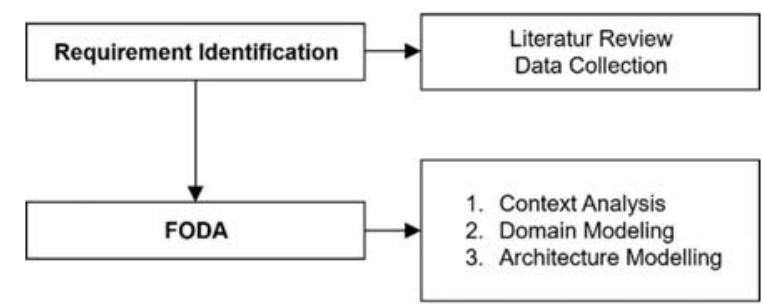

Fig. 1. Research Method

\section{A. Requirement Identification}

This stage conducted the literature review and data collection. At the literature review stage, researchers conducted a library search related to online learning, LMS, Feature-Oriented Domain Analysis (FODA), and SN-Dikti. In this phase, researchers also register and try out all the LMS assignment and assessment features analyzed, namely Edmodo, Moodle, and Google Classroom. Furthermore, after a list of all features is obtained, the researcher selects the features based on a joint assessment by experts, to receive assessment and assignment features. The results of the feature selection will be analyzed and recommended again for the new LMS.

\section{B. FODA}

FODA is a method resulting from the study of domain analysis approaches, which provides a view of the needs and architectural aspects of the assets that will rebuild. This method focuses on identifying the product, system, or technology features in a domain that has been well defined [6]. The FODA method has several phases, including 1) the context analysis, 2) domain modeling, and 3) the architecture modeling [5].

\section{1) Context Analysis}

Context Analysis is the stage to find out or determine the scope of the domain that tends to produce domain products that can be extracted or provide data. In context, the analysis will create a context diagram that explains the process that exists in the domain.

\section{2) Domain modeling}

Domain modeling is an advanced stage of context analysis, where the model can identify the domains through analyzed similarities and differences and also the relationships between entities in the related area. In the domain modeling phase, there are three primary stages, namely feature analysis, entity-relationship modeling, and functional analysis.

\section{3) Architecture Modeling}

The purpose of architectural modeling is to provide software solutions problems defined in previous domain modeling. The main goal of FODA is to make domain products reusable. In the development of architectural modeling is a high-level application design in the domain that focuses on the identification of processes, the allocation of features, functions, and data objects defined in domain modeling.

\section{RESULT AND DISCUSSION}

This stage explains the results and review of the research, beginning with data collection and FODA Analysis.

\section{A. Data Collection}

The researcher simulates all the assessment and assignment features found in the three LMS to gain experience using each LMS feature. Then each feature will be recorded and labeled. After that, we eliminated the duplicate elements so we can found the unique feature from the three LMS. At this stage, 54 features obtained for lecturer and student users.

At this stage, the researcher identified the SN-Dikti assessment standards contained in Permenristekdikti No. 44 of 2015. Table 1 shows the result of assessmentstandards.

TABLE 1 List OF COMPONENTS OF SN DiKTI AsSESSMENT STANDARDS

\begin{tabular}{|l|l|}
\hline Code & SN-Dikti Assessment Standards \\
\hline SP01 & Principles of Educational Assessment \\
\hline SP02 & Principles of Authentic Assessment \\
\hline SP03 & Principles of Objective Assessment \\
\hline SP04 & Principles of Accountable Assessment \\
\hline SP05 & Principles of Transparent Assessment \\
\hline SP06 & Principles of Integrative Assessment \\
\hline SP07 & Observation Evaluation Techniques \\
\hline SP08 & Participatory Assessment Techniques \\
\hline SP09 & Performance Evaluation Techniques \\
\hline SP10 & Written Test Assessment Techniques \\
\hline SP11 & Oral Test Assessment Techniques \\
\hline SP12 & Questionnaire Assessment Techniques \\
\hline SP13 & Rubric Instruments \\
\hline SP14 & Portfolio Assessment Instrument \\
\hline SP15 & Assessment Mechanisms \\
\hline SP16 & Planning Procedure Assessment Procedure \\
\hline SP17 & Procedure for Evaluating Tasks / Questions \\
\hline SP18 & Procedure for Evaluation of Performance Observation stage \\
\hline SP19 & Procedure for Evaluation of Return Observation stage \\
\hline
\end{tabular}




\begin{tabular}{|l|l|}
\hline Code & SN-Dikti Assessment Standards \\
\hline SP20 & Procedure for Evaluating the Final Grading stage \\
\hline SP21 & Implementation of Assessment \\
\hline SP22 & Implementation of Assessment by Lecturers / Students \\
\hline SP23 & Reporting Assessment \\
\hline
\end{tabular}

The next stage is mapping 54 features of LMS with 23 SN-Dikti assessment standards in Table 1. Mapping results are verified by experts through semi-structured interviews, concerning the list of questions but can develop as needed. Researchers involved three experts in the field of education. The verification results are in the form of a pair of feature lists with a rating standard.

\section{B. FODA}

Analysis FODA is used to analyze LMS features through three stages to compile new LMS system requirements based on the reference LMS feature model. FODA is used because this method can provide several ways of applying the results of domain analysis to support software development, besides FODA supports the reuse of features from a pre-existing system. Detailed stages of LMS feature analysis has explained as follows:

\section{1) Context Analysis}

The context diagram illustrated the scope of the analyzed domain. Following its function, the context diagram serves to explain the data flow that occurs in the LMS.

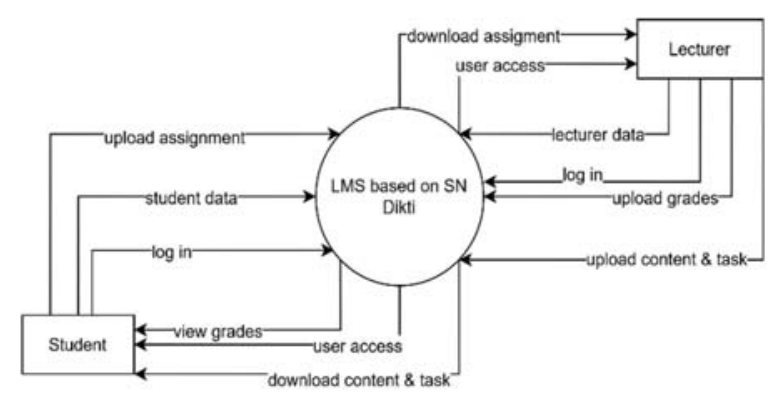

Fig. 2. Context Diagram

Referring to the context diagram, on the assignment and assessment functions, the analyzed LMS used by two actors, namely Students and Lecturers. Each actor has different access rights, according to the needs of the actor.

\section{2) Domain Modeling}

At the domain modeling stage, a study of the similarities and differences in LMS features that have been limited based on the context diagram in Figure 2. The domain modeling phase starts with feature analysis, entityrelationship modeling, and functional analysis [5].

\section{a) Feature Analysis Feature}

The analysis was performing to explore the understanding of LMS end-users about the general capabilities of the application. At this stage, the researcher will analyze each feature on the three LMS. The output of feature analysis is the feature requirements of the LMS system. Researchers found the need for LMS features based on SN-Dikti. In the future LMS, the grade features must become the main features (mandatory), while the assignment, quiz, and question features become alternative features. Mandatory and entity features are the basis of the functional model. While alternative and optional features will be added during the system development process. Figure 2 shows the analysis of LMS features.

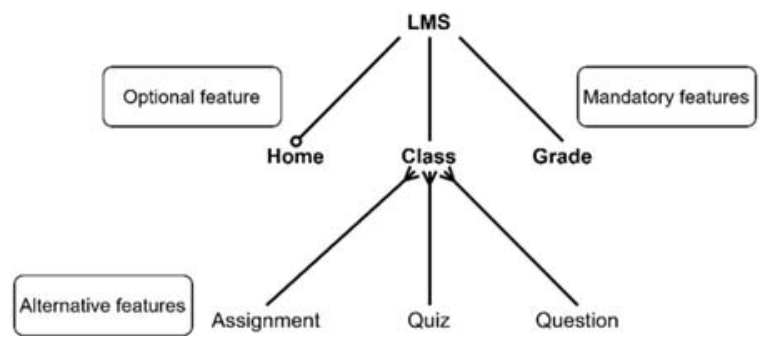

Fig. 3. Analysis of LMS Features

\section{b) Entity Relationship Modeling}

The main goal of entity-relationship modeling is to support the analysis based on the entities required by the new LMS as well as to arrange domain objects that will be used in later development process. In this study, Figure 3 detailed entity-relationship modeling.

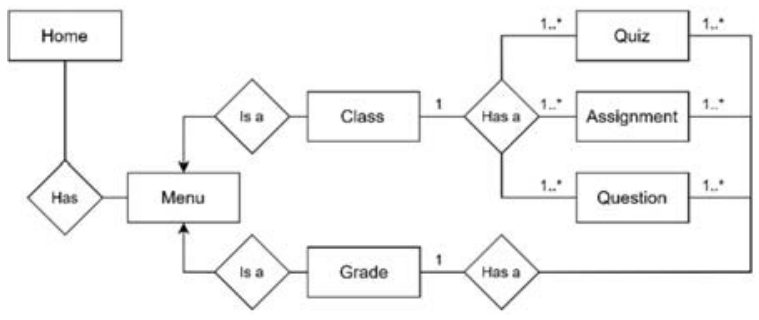

Fig. 4. Modeling Entity Relationship LMS Features

In the picture can be seen on the home menu, there are two main menus, namely class, and grade, the class has three entities, namely quiz, assignment, and question. Operations on each of these entities will produce grades. Relations between entities are strengthened by cardinality between entities. For example, class entities have three derived entities, namely quiz, assignment, and question with many - one to many relations, which means that in one class, there are at least one to many quizzes, and soon.

\section{c) Functional Analysis}

The functional analysis aims to identify the similarities and functional differences of LMS in a domain. Functional model specifications can be classified into two main categories: function specifications and behavior specifications. Function specifications describe the structural aspects of an application in terms of inputs, outputs, activities, internal data, logic structures, and data flow relationships. Behavior specifications describe how applications behave in terms of events, inputs, and conditions.

Based on the feature analysis before, four activity diagrams can describe the behavior of the LMS features that have analyzed. Figure 4 gives an example activity diagram of a class feature. 


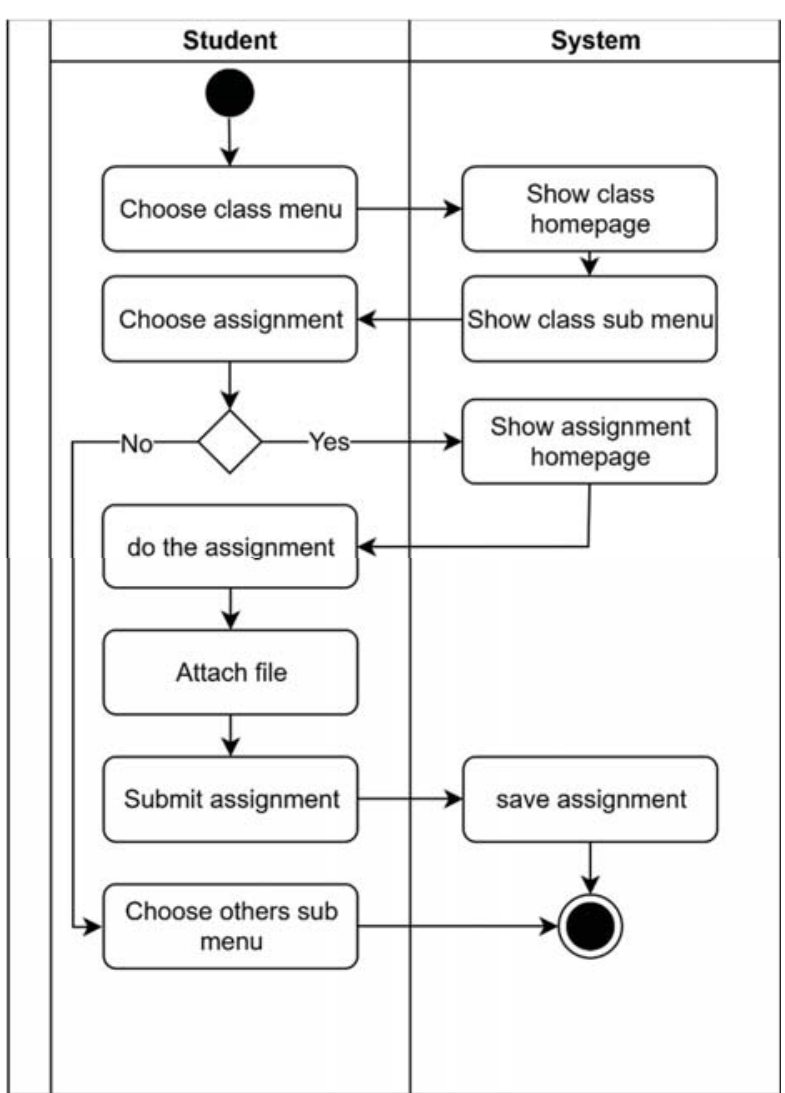

Fig. 5. Activity Diagram assignment features

The activity diagram in Figure 4 explains that the home menu contains class menus and sub-menu assignments. When the user selects the assignment menu, several tasks can be displayed by the user. Users can attach files and submit tasks to the system. The system will save the attachments of the task and display the grade of the completed task.

\section{3) Architectural Modeling}

In the last stage, architectural modeling carried out, which aims to produce a system architecture for the LMS domain model. The system architecture used to develop LMS system applications later, which focuses on adding features based on domain requirements. The architectural model aims to maintain the consistency of the product model that is produced at the time of development, for example, when adding new features without having to change the basis of product manufacture [10]. Figure 5 detailed the architectural modeling in this case.

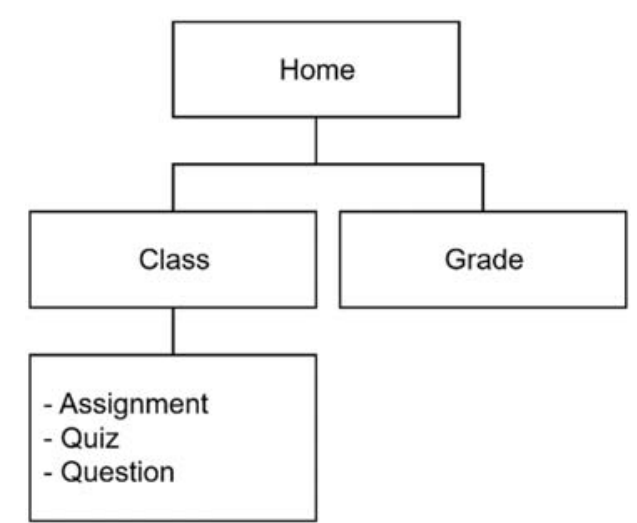

Fig. 6. Architectural Modeling of LMS

Based on Figure 5, it can be seen that in the LMS menu, the assessment and assignment domains are in the class menu that has an assignment, quiz, and question sub-menus. Besides the class menu, the grading domain is also in the grade menu.

\section{Analysis of Results and Recommendations}

At this stage, the list of recommendations for functional features is compiled, which will be embedded into a new LMS with features based on SN-Dikti according to expert validation. Expert validation aims to interpret the data that has been successfully collected in the past phase and to verify the results of the analysis [11].

One of the results of expert validation on the results of mapping LMS features with SN Dikti, for example, is the principle of objective assessment. Objective assessment is an assessment of what it is. Students are judged based on what they do, one way to find out the assessment by creating a rubric that explains the points of assessment on the assignments given. Besides that, the main key in the principle of objective evaluation is a procedure. The procedure is a stage that must be done by students in completing assignments/projects. The procedure is already listed in the assessment rubric so that the lecturer can assess the suitability of the procedure based on the assessment rubric. Therefore experts recommend the document insertion feature, which can contain rubric documents.

The results of this study recommend new LMS features presented in the form of functional feature tables and an explanation of each feature. This recommendation can be a reference for LMS developers, specifically in the assignment and assessment domain. The list and explanation of LMS useful feature recommendations for Lecturers and Students are described as follows:

\section{1) Lecturer}

Assessment and assignment features for Lecturer users should be based on SN-Dikti's assessment standards. For example, assignments and assessments must refer to the educational appraisal principle (SP01)

For this reason, the recommended LMS feature has a reporting and evaluation function for student strengths and weaknesses. One example is providing feedback on student work (FB024). Each recommended assessment standard has built on the same pattern, so it has strong arguments - the 
list of recommended features for LMS users described in Table 2.

TABLE 2 LIST OF RECOMMENDED FEATURES FOR LECTURERS

\begin{tabular}{|c|c|}
\hline Code & Recommended LMS Features \\
\hline FB001 & Lecturers can create classes \\
\hline FB002 & Lecturers can add other lecturers \\
\hline FB003 & Lecturers can make announcements \\
\hline FB004 & Lecturers can insert documents in the announcement \\
\hline FB006 & Lecturers can make Assignments \\
\hline FB007 & Lecturers can make an Assignment description \\
\hline FB008 & Lecturers can make Assignments for groups \\
\hline FB009 & Lecturers can insert documents in Assignment \\
\hline FB011 & Lecturers can provide the deadline for Assignment collection \\
\hline FB013 & Lecturers can add Assignments to grade books \\
\hline FB014 & Lecturers can make quizzes \\
\hline FB015 & Lecturers can describe quizzes \\
\hline FB016 & Lecturers can determine the quiz deadline \\
\hline FB017 & The lecturer can determine the points for each quiz question \\
\hline FB018 & $\begin{array}{l}\text { Lecturers can provide time limits Students can work on } \\
\text { quizzes }\end{array}$ \\
\hline FB019 & Lecturers can add Quiz to grade book \\
\hline FB020 & Lecturers can add comments on each post \\
\hline FB021 & Lecturers can download the assignment results \\
\hline FB022 & $\begin{array}{l}\text { Lecturers can see students who have submitted assignments or } \\
\text { not }\end{array}$ \\
\hline FB023 & Lecturers can give Assignment scores to students \\
\hline FB024 & Lecturers can provide comments on Student Assignment \\
\hline FB025 & Lecturers can see students who have worked on the quiz or not \\
\hline FB026 & $\begin{array}{l}\text { Lecturers can provide comments (feedback) on each Student } \\
\text { quiz answers }\end{array}$ \\
\hline FB027 & Lecturers can make questions \\
\hline FB028 & Lecturers can make question instruction \\
\hline FB029 & Lecturers can provide a deadline for Question collection \\
\hline FB030 & Lecturers can make topic questions \\
\hline FB031 & Lecturers can insert documents in Question \\
\hline FB032 & Lecturers can give a question value to students \\
\hline FB033 & Lecturers can provide comments on student questions \\
\hline FB034 & Lecturers can share grades with students \\
\hline FB035 & Lecturers can see replies between students \\
\hline FB036 & Lecturers can see $\mathrm{p}$ progress of students \\
\hline FB037 & Lecturers can see the value of students for one period \\
\hline
\end{tabular}

\section{2) Student}

Assessment and assignment features for Student users are also recommended based on the SN-Dikti assessment standard. For example, the Participatory valuation technique (SP08). In the method of participatory assessment, the lecturer looks at the extent of student involvement in learning and how active students are in discussion. The pattern used in learning will involve several components, this assessment technique also provides an opportunity for students to do peer assessment, so that the assessment and assignment features in the LMS that recommended for Student users can give a review of other student assignments (FB048). A list of recommended LMS features for Student users described in Table 3.

TABLE 3 Lists ReCOMMENDED FEATURES FOR STUdENT

\begin{tabular}{|l|l|}
\hline \multicolumn{1}{|c|}{ Code } & Recommended LMS Features \\
\hline FB038 & Students can post replies \\
\hline FB040 & Students can do Assignments \\
\hline FB041 & Students can attach documents in assignments \\
\hline FB042 & Students can make comments to the instructor on assignments \\
\hline FB044 & Students can see the Quiz description \\
\hline FB045 & Students can work on quizzes \\
\hline FB046 & Students can see the question description \\
\hline FB047 & Students can answer questions \\
\hline FB048 & a student can give a reply to his friend's answer in question \\
\hline FB049 & Students can see the value of Assignment \\
\hline FB050 & $\begin{array}{l}\text { Students can see lecturers' comments / feedback on } \\
\text { assignments }\end{array}$ \\
\hline FB051 & Students can see the results of the quiz \\
\hline FB052 & Students can see lecturer comments/feedback in the quiz \\
\hline FB053 & Students can see the value of the question \\
\hline
\end{tabular}

Recommended features for assignment and assessment activities on e-learning are on the home, class, and grade pages. Class pages can be specified as assignments, quizzes, and questions. From the results of the analysis of 3 LMS with FODA, 34 functional features were formulated for Lecturer users and 14 functional features for Student users. All recommended features have been verified by experts and mapped to SN Dikti's assessment standards.

\section{CONCLUSION}

Based on the results of the research that has been done, the conclusion is formulated that based on the results of domain analysis and a list of recommended features that have been validated by experts, the LMS that is most suitable for SN-Dikti for assessment features for lecturers is Edmodo by $81 \%$, Google Classroom by $73 \%$, and Moodle by $51 \%$. As for the assessment features for students who are most in line with SN-Dikti are Edmodo by $76 \%$, Google Classroom by $71 \%$, and Moodle by $59 \%$.

\section{ACKNOWLEDGMENT}

The object of this research based on the use of LMS at the Universitas Muhammadiyah Malang (UMM). Besides that, this research funding through a research grant from the UMM.

\section{REFERENCES}

[1] N. Cavus, "Selecting a learning management system (LMS) in developing countries: Instructors' evaluation," Interact. Learn. Environ., vol. 21, no. 5, pp. 419-437, Oct. 2013.

[2] C. K. Chen and M. N. Almunawar, "Cloud Learning Management System in Higher Education," no. September, pp. 29-51, 2019.

[3] G. Durak, "Using social learning networks (SLNs) in higher education: Edmodo through the lenses of academics," Int. Rev. Res. Open Distance Learn., vol. 18, no. 1, pp. 84-109, 2017.

[4] T. Rodmunkong, P. Wannapiroon, and P. Nilsook, "The architecture of Information Management System through cloud computing according to Thai Qualifications Framework for Higher Education,' 
Proc. 2015 IEEE Int. Conf. Teaching, Assess. Learn. Eng. TALE 2015, no. December, pp. 181-188, 2016.

[5] K. C. Kang, S. G. Cohen, J. a Hess, W. E. Novak, and a S. Peterson, "Feature-Oriented Domain Analysis (FODA) Feasibility Study," Distribution, vol. 17, no. November, p. 161, 1990.

[6] C. Marimuthu and K. Chandrasekaran, "Feature-Oriented Domain Analysis Framework for Energy-Aware Self-Adaptive Software," Proc. - 2016 IEEE Int. Conf. Internet Things; IEEE Green Comput. Commun. IEEE Cyber, Phys. Soc. Comput. IEEE Smart Data, iThings-GreenCom-CPSCom-Smart Data 2016, pp. 773-776, 2017.

[7] U. F. Muhammad Yaseen, "Requirement Elicitation Model (REM) in the Context of Global Software Development," Glob. J. Comput. Sci. Technol., 2018.

[8] N. Harrati, I. Bouchrika, A. Tari, and A. Ladjailia, "Exploring user satisfaction for e-learning systems via usage-based metrics and system usability scale analysis," Comput. Human Behav., vol. 61, pp. 463-471, Aug. 2016

[9] H. B. Santoso, M. Schrepp, R. Yugo Kartono Isal, A. Y. Utomo, and B. Priyogi, "Measuring user experience of the student-centered Elearning environment," J. Educ. Online, vol. 13, no. 1, pp. 1-79, Jan. 2016

[10] M. I. A. A. . M. R. F. I. Budiman, "Penentuan Fitur Website Bidang Pariwisata Dan Kebudayaan Dengan Metode Feature-Oriented Domain Analysis ( FODA )," Kumpul. J. Ilmu Komput., vol. 03, no. September, pp. 172-181, 2016.

[11] M. A. Meyer and J. M. Booker, Eliciting and Analyzing Expert Judgement, SIAM Editi. London: Academic Press Limited, 2001. 